\title{
ISOLATION AND IDENTIFICATION OF FUNGI FROM MUSHROOM COMPOSTS AND EVALUATION OF THEIR BIOLOGICAL ACTIVITYY
}

\author{
RAMANI WICKREMASINGHE ${ }^{1}$, KRISHANTHI ABEYWICKRAMA ${ }^{2 *}$ and \\ D.T.U. ABEYTUNGA:
}

${ }^{1}$ Department of Botany, University of Kelaniya, Kelaniya

2 Department of Botany, University of Colombo, Colombo 3

${ }^{3}$ Department of Chemistry, University of Colombo, Colombo 3.

(Received: 4 February 1998 ; accepted 9 April 1999)

\begin{abstract}
Four species of fungi namely, Aspergillus fumigatus, Chetomium thermophile, Mucor pusillus and Trichoderma harzianum were isolated and identified from straw and oyster compost substrates collected from the research station of Export Development Board, Ratmalana, Sri Lanka. Frequency of occurrence of contaminants, Aspergillus fumigatus and Trichoderma harzianum was $100 \%$ irrespective of the stage of processing of composts. Crude aqueous extracts of A. fumigatus and T.harzianum showed antifungal activity against three plant pathogens at fairly high concentrations (5000 and $10,000 \mu \mathrm{g})$. A. fumigatus and T. harzianum crude aqueous extracts prepared after growing the two fungi on two selected liquid media, when tested, showed antibacterial activity against three human pathogenic bacteria at relatively low concentrations $(10-40 \mu \mathrm{g})$. Partially purified aqueous fractions of both A. funigatus and T. harzianum demonstrated considerable antibacterial activity against Streptococcus viridans and Staphylococcus aureus.
\end{abstract}

Key words: Antibacterial activity, antifungal activity, Aspergillus fumigatus, mushroom compost, Trichoderma harzianum.

\section{INTRODUCTION}

Straw mushroom (Volvariella volvacea) and oyster mushroom (Pleurotus spp.) are cultivated at the research station of Export Development Board (EDB), Ratmalana, Sri Lanka, to develop growth conditions and improve yields of mushrooms for local consumption and export. Oyster compost samples are packed in polybags and subjected to steam sterilization before mushroom spawn is introduced. Components of straw mushroom compost once mixed are only subjected to a self heating process where temperature of compost piles should theoretically. increase to about $70^{\circ} \mathrm{C}$ due to natural activity of microbes in composting substrates. ${ }^{1}$ High temperature environments within compost substrates, during the 2 different composting procedures should remove plant pathogenic, saprophytic, parasitic fungi as well as insects and other unwanted microorganisms. However, complete elimination of unwanted mycoflora does not take place during the composting processes. Many thermophilic, heat tolerant and mesophilic fungal contaminants remain. The above fungi can contaminate the spawn added to various mushroom compost substrates, leading to unusual discoloration of the substrates. The

"Corresponding author

2 Present address: Department of Botany, University of Kelaniya, Kelaniya. 
surviving fungal flora can compete with mushroom spawn for nutrients, moisture, and could also act as antagonistic organisms to mushroom mycelia, leading to the reduction in the yield of mushroom fruit bodies, affecting the quality of the final product. One objective of our research project was to identify and isolate mycoflora which survive self heating or high temperature treatment in mushroom composts. The second objective was to screen the identified mycoflora for their capacity to produce biologically active compounds such as antifungal and antibacterial substances on selected media.

\section{METHODS AND MATERIALS}

Isolating and identifying fungi from compost: Straw compost ( straw, horse manure, kapok waste, water) and Oyster compost (saw dust, rice bran, calcium carbonate, magnesium sulphate, water) samples were collected from EDB Research Station in Ratmalana, Sri Lanka. Oyster mushroom compost samples were at different stages as follows: a) after packing in polybags, no visual contamination, b) after packing, contaminated with mold flora, c) samples in polybags to which mushroom spawn had been added, no visual contamination, d) samples after addition of spawn which are contaminated with mold flora. Total of 8 polybags of oyster compost at a-d stages were randomly selected from a series of polybags arranged on shelves inside a mushroom cultivation shed. From each polybag $3 \times 1 g$ samples of compost were withdrawn randomly for isolating fungi (total \# of samples from 4 stages $=24$ ). Straw mushroom samples were collected, 1) during the self heating process where the temperature of piles would have been around $70^{\circ} \mathrm{C}$ and 2) after spawn has been added. Twenty $1 \mathrm{~g}$ (ten from each stage) compost samples were collected randomly from different areas of 4 compost piles (five samples/pile). Oyster and straw compost samples were sprinkled on yeast extract starch agar (soluble starch $15.0 \mathrm{~g}$, yeast extract $4.0 \mathrm{~g}, \mathrm{~K}_{2} \mathrm{HPO}_{4} 1.0 \mathrm{~g}, \mathrm{MgSO}_{4} .7 \mathrm{H}_{2} \mathrm{O} 0.5 \mathrm{~g}$, distilled water 11) and plates were placed inside a moist chamber (glass tank lined with several layers of moist filter paper), incubated in an incubator (Sanyo, model MIR262 ) at $30,35,40,45,50^{\circ} \mathrm{C}$ for 7 days. $^{1}$ (10 replicate plates/temperature). Isolated fungi were transferred to yeast extract starch agar slants for identification and storage. Pure cultures of isolated fungi were prepared and identification was carried out with the aid of slide cultures, temporary mounts and published keys/books . ${ }^{1-3}$

Preparation of liquid cultures: Isolated Aspergillus fumigatus was grown on yeast extract starch agar plates and incubated for 10 days at $30^{\circ} \mathrm{C}$. Yeast extract starch liquid medium was used to promote the growth of the above fungus. ${ }^{1}$ Fifteen Erlenmeyer flasks each containing $100 \mathrm{ml}$ of medium were sterilized at $121^{\circ} \mathrm{C}$ and $1.03 \mathrm{~kg} \mathrm{~cm}^{-2}$ pressure for $20 \mathrm{~min}$. Each cooled flask was inoculated aseptically with 2 discs of $0.5 \mathrm{~cm}$ diameter pure culture of Aspergillus fumigatus and flasks were incubated for 12 days at $30^{\circ} \mathrm{C} .{ }^{1}$ Isolated Trichoderma harzianum was grown on a liquid medium (maltose $20.0 \mathrm{~g}$, glucose $10.0 \mathrm{~g}$, peptone $2.0 \mathrm{~g}$, yeast extract $1.0 \mathrm{~g}$, 
$\mathrm{MgSO}_{4} 0.5 \mathrm{~g}, \mathrm{~K}_{2} \mathrm{HPO}_{4} 0.5 \mathrm{~g}, \mathrm{CaCl}_{2} 0.05 \mathrm{~g}, \mathrm{FeCl}_{33} 0.01 \mathrm{~g}, \mathrm{ZnSO}_{4} 0.01 \mathrm{~g}$, distilled water 11). Fifteen Erlenmyer flasks containing ( $100 \mathrm{ml}$ each) medium were inoculated aseptically with 2 discs of $0.5 \mathrm{~cm}$ diameter of a pure culture of $T$. harzianum grown on yeast extract starch agar, and the flasks were incubated at $30^{\circ} \mathrm{C}$ for 21 days $:^{4,5}$ After incubation period liquid media were separated from Aspergillus or Trichoderma fungal mats by filtering through Whatman No. 1 filter paper. Filtrates from 10 flasks (for each fungus) were pooled, $\mathrm{pH}$ noted, freeze dried and saved for bioassays. ${ }^{4.5}$

\section{Bioassays for antifungal activity:}

(1) Disc diffusion bioassay- Crude residues (2 mg each) of A. fumigatus and T. harzianum were dissolved in $0.5 \mathrm{ml}$ of water. Pure cultures of three plant pathogenic fungi, namely Fusarium oxysporum, Rhizoctonia solani, and Colletotrichum lindemuthianum were selected as test organisms. Cultures of the 3 test fungi in slants were transferred to petri dishes containing potato dextrose agar (PDA). After one day, sterile filter paper discs (Whatman \# 40, diameter $1.3 \mathrm{~cm}$ ) impregnated with various levels of $A$. fumigatus crude extracts (to give concentrations of 100-1000 $\mu \mathrm{g}$ ) were placed on plates about $2 \mathrm{~cm}$ away from the margin of each plate. Three discs/concentration/test organism and one water control was used per plate. 'The total number of plates used per selected level of extract per test organism was fifteen. All plates were incubated for 1-4 days at $30^{\circ} \mathrm{C}$. Inhibition effect of crude extracts of A. fumigatus on each test organism was recorded by measuring diameters of inhibition zones of treatments and comparing them with the controls. ${ }^{4-l i}$ The above bioassay was repeated using higher levels (1000-10,000 $\mu \mathrm{g}$ ) of crude extracts of $A$. fumigatus. The same bioassay was adapted to test the antifungal properties of aqueous crude extracts of T. harzianum; the experimental conditions were identical to the ones used for A. fumigatus.

(2) Cladosporium TLC bioassay - Cladosporium cladosporoides spore suspensions were prepared in the following manner: Cladosporium was grown on PDA medium and incubated for 10 days at $30^{\circ} \mathrm{C}$. A pure culture of 7-8 day old Cladosporium grown on PDA medium in $100 \mathrm{ml}$ Erlenmeyer flasks was selected for the bioassay. A $25 \mathrm{ml}$ portion of Czapex dox nutrient liquid medium (sucrose $30.0 \mathrm{~g}, \mathrm{KNO}_{3} 2.0 \mathrm{~g}$, $\mathrm{K}_{2} \mathrm{HPO}_{4} 1.0 \mathrm{~g}, \mathrm{MgSO}_{4} .7 \mathrm{H}_{2} \mathrm{O} 0.5 \mathrm{~g}, \mathrm{KCl} 0.5 \mathrm{~g}, \mathrm{FeSO}_{4} .0 .01 \mathrm{~g}$, distilled water 11) was poured into culture flasks and shaken for $20 \mathrm{~min}$ on a shaker (IUCHI SEIEDO, model SRR-2) to facilitate release of conidia. ${ }^{6,7}$ The suspension was filtered through a muslin cloth and the conidia in the filtrate were adjusted to $5 \times 10^{6}$ conidia per ml. ${ }^{6,7}$ Crude residue ( $2 \mathrm{mg}$ ) of Aspergillus fumigatus dissolved in $0.5 \mathrm{ml}$ of methanol:water (1:1) mixture was spotted on five silica gel 60 F-254 plates $(5 \mathrm{~cm} \times 20 \mathrm{~cm})$ and the plates were placed in a glass tank and developed in ethyl acetate:hexane (1:1) mobile phase. The developed plates were air-dried and sprayed with a suspension of conidia of Cladosporium in Czapex dox nutrient solution and incubated in a moist chamber for $48 \mathrm{~h}$ at $30^{\circ} \mathrm{C}$. Presence of inhibition zones (white) was noted against a green background..$^{6.7}$ The above experiment was repeated using crude extracts of T. harzianum. 
Bioassay for antibacterial activity:

(1) Disc diffusion bioassay - Four species of human pathogenic bacteria namely, Streptococcus viridans, Staphylococcus aureus, Klebsiella aerogenes and Escherichia coli were selected as test organisms. Each bacterial species was grown on $50 \mathrm{ml}$ nutrient broth cultures in Erlenmeyer flasks and incubated for 1 day at $30^{\prime \prime} \mathrm{C}$. A dilution series of each culture was prepared ascptically to study the growth (density) of each bacterium. Dilution $10^{-3}$ which contained about $2 \mathrm{x}$ $10^{3} \mathrm{cells} / \mathrm{ml}$ was selected as the most suitable dilution. A set of 15 nutrient agar plates were inoculated with $0.5 \mathrm{ml}$ of selected dilution of each bacterium and inoculum was spread evenly with the aid of a sterile glass rod. Plates were incubated for $30 \mathrm{~min}$. Three sterile filter paper dises (Whatman \# 40, diameter $1.3 \mathrm{~cm}$ ) impregnated with various volumes of aqueous crude extracts of A. fumigatus (to give concentrations of $10-40 \mu \mathrm{g}$ ) were placed on incubated agar plates about $2 \mathrm{~cm}$ from the edge of each plate. One disc moistened with sterile distilled water (control) was also placed in each plate. The size of inhibition zones around the discs (indicating antibacterial activity) were measured after 1-2 day incubation period at $30^{\circ} \mathrm{C} .^{4,6}$ The above bioassay was repeated using higher levels $(50-2000 \mu \mathrm{g})$ of the same crude extract. The same bioassay was adapted to test the antibacterial activity of $T$. harzianum; the experimental conditions were identical to the ones used for A. fumigatus. ${ }^{4.65}$

(2) Hamburger \& Cordell bioautographic TLC assay - Forty eight hour old bacterial cultures of Staphylococcus aureus and Streptococcus viridans in nutrient broth cultures were centrifuged at $\times 2000 \mathrm{~g}$ in a refrigerated high speed microcentrifuge (KOKUSAN ENSHINKI, model H-1500 SR). Liquid portion was discarded and the pellets were mixed with $20 \mathrm{ml}$ of fresh nutrient agar broth to prepare each bacterial suspension. Crude residue ( $2 \mathrm{mg})$ of $A$. fumigatus dissolved in $0.5 \mathrm{ml}$ of methanol:water (1:1) was spotted on ten silica gel $60 \mathrm{~F}-254$ plates $(5 \mathrm{~cm} \times 20 \mathrm{~cm})$ and the plates were developed in a glass tank containing ethyl acetate:hexane (1:1). Five air dried plates were sprayed with Staphylococcus and another five with Streptococcus bacterial broth suspension. All TLC plates were incubated in a humid chamber (glass tank) at $30^{\circ} \mathrm{C}$ overnight. Plates were sprayed with a solution of tetrazolium chloride $(20 \mathrm{mg} / \mathrm{ml})$ and incubated in a moist chamber at $37^{\circ} \mathrm{C}$ for $4 \mathrm{~h}$ and plates treated with $70 \%$ alcohol were checked for white inhibition zones against a pink background after one day. $\$$ The same bioassay was repeated using crude residue $(2 \mathrm{mg})$ of $T$. harzianum.

Extraction of active compounds from the fungal residues: Aspergillus fumigatus and Trichoderma harzianum crude residues from culture filtrates were subjected to a solvent extraction procedure in order to facilitate the separation and purification of active compounds. Hexane, ethyl acetate, methylene chloride, ether and methanol $(5 \mathrm{ml}$ each) were used as solvents. Weight of residues in each fraction was recorded after vapourizing the solvents on a rotavapour (BUCHI, model 912439)." Known weights of residues of $A$. fumigatus and $T$. harzianum were dissolved in 
water and the disc diffusion bioassay was carried out using different volumes of extracts (to give 10-100 $\mu \mathrm{g}$ concentrations). The test organisms used were Streptococcus viridans, Staphylococcus aureus, $K$. aerogenes and E.coli. ..G $^{.6}$

\section{Purification and separation of active fractions using column and thin layer chromatography:}

(a) Residues of methanol fraction of A. fumigatus (obtained from the previous experiment) were purified on a silica gel-60 column using $50 \mathrm{ml}$ each of methylene chloride:methanol (7:3), and methylene chloride:methanol (6:4) and pure methanol. Three fractions collected from the column were spotted on silica gel-60 TLC plates $(20 \times 20 \mathrm{~cm})$ and the plates were developed in a moist chamber using methylene chloride: methanol (7:3) as the mobile phase." Three fractions - AM-1, AM-2 and AM-3 were identified under long wave uv ( $356 \mathrm{~nm}$ ). Methanol was removed using a rotavapour and the three fractions were dissolved in $0.5 \mathrm{ml}$ each water. Various volumes of aqueous fractions (to give concentrations of 10-40 $\mu \mathrm{g}$ ) were tested for antibacterial activity against Streptococcus viridans and Staphylococcus aureus using the disc diffusion method and Hamburger and Cordell assay. ${ }^{4.8}$

(b) Similarly the components in the ethyl acetate fraction of $T$. harzianum were separated on a silica gel-60 column using $50 \mathrm{ml}$ each of ethyl acetate:hexane $(1: 1)$ and ethyl acetate hexane (8:2) and pure ethyl acetate. Three fractions collected from the column were spotted on TLC as in step (a) and the plates were developed using ethyl acetate: hexane (1:1) mobile phase." Three fractions - TE-1, TE-2 and TE-3 were identified under long wave uv light. Organic solvents were removed using a rotavapour and the three fractions dissolved in water was subjected to antibacterial activity test on Streptococcus viridans and Staphylococcus aureus using disc diffusion method and the Hamburger \& Cordell assay. ${ }^{4.8}$ The experimental conditions were identical to the ones adapted in step (a).

(c) Methanol fraction of T. harzianum was separated into components on a silica gel-60 column using $50 \mathrm{ml}$ each methanol:methylene chloride $(3: 7)$ and methanol:methylene chloride (4:6) and pure methanol. Four fractions collected from the column were spotted on a TLC plate and the plates were developed in methanol:methylene chloride (3:7) mobile phase. ${ }^{9}$ Four fractions - TM-1, TM-2, TM-3 and TM-4 identified under uv were subjected to antibacterial bioassay as in step (b). 4.8

\section{RESULTS}

Four species of fungi namely Aspergillus fumigatus, Chaetomium thermophile, Mucor pusillus and Trichoderma harzianum were isolated and identified from straw and oyster mushroom compost samples incubated at a range of temperatures. Mucor pusillus was isolated at a frequency of $50 \%$ and $60 \%$ respectively from 
yeast extract starch agar plates incubated at 5 different temperatures after sprinkling oyster and straw compost samples taken from different stages of processing. Chaetomium thermophile could be isolated at a lower frequency of $30-35 \%$ from plates sprinkled with oyster and straw composts. T. harzianum and $A$. fumigatus occurred in all plates ( $100 \%$ frequency) incubated with both types of compost samples at temperatures of $30-50^{\circ} \mathrm{C}$, irrespective of the stage of processing of composts.

When antifungal activity of crude extracts of $A$. fumigatus and T. harzianum. was checked using the disc diffusion bioassay, inhibitory effect on the colony growth of the 3 test fungi- Rhizoctonia solani, Fusarium oxysporium and Colletotrichum lindemuthianum was observed at fairly high levels of 5000 and 10,000 $\mu \mathrm{g}$. The effect of $A$. fumigatus and T.harzianum crude extracts on $F$. oxysporum was more prominent at 5000 and $10,000 \mu \mathrm{g}$ levels. Results indicated a $16.7 \%$ and $30 \%$ mean reduction of colony radius $(\mathrm{cm})$ of $F$. oxysporum exposed to 5000 and $1.0,000 \mu \mathrm{g}$ levels of crude extracts of $A$. fumigatus respectively. The mean reduction of the colony radius of the same fungus exposed to the crude extracts of $T$. harzianum was $13.4 \%$ and $50 \%$ at 5000 and $10,000 \mu \mathrm{g}$ levels respectively. However, the same test fungi were insensitive to lower levels (100-1000 $\mu \mathrm{g})$ of crude extracts from both $A$. fumigatus and $T$. harzianum.

When antifungal activity of crude extracts of $A$. fumigatus and T. harzianum was tested using Cladosporium TLC bioassay, clear inhibition zones could not be detected.

Staphylococcus aureus, Streptococcus viridans and $K$. aerogenes were inhibited at relatively high $(50-2000 \mu \mathrm{g})$ and low $(10-40 \mu \mathrm{g})$ levels of crude extracts of A. fumigatus during disc diffusion antibacterial bioassay (Table 1). E.coli showed sensitivity to A. fumigatus extracts at $30-40 \mu \mathrm{g}$ levels and no sensitivity at lower levels.

Table 1: Mean diameter of the inhibition zones $(\mathrm{cm})$ of test bacterial colonies exposed to aqueous crude extracts of A. fumigatus compared to sterile water (control).

\begin{tabular}{|c|c|c|c|c|c|}
\hline \multirow[b]{2}{*}{ Test bacteria } & \multicolumn{3}{|c|}{ Level of extract $(\mu \mathrm{g})$} & \multirow[b]{2}{*}{40} & \multirow[t]{2}{*}{ Control. } \\
\hline & 10 & 20 & 30 & & \\
\hline $\begin{array}{l}\text { Staphylococcus } \\
\text { aureus }\end{array}$ & $1.6 \pm 0.2$ & $1.8 \pm 0.1$ & $2.0 \pm 0.2$ & $2.2 \pm 0.1$ & no effect \\
\hline $\begin{array}{l}\text { Streptococcus } \\
\text { viridans }\end{array}$ & a $1.8 \pm 0.1$ & $2.0 \pm 0.1$ & $2.1 \pm 0.2$ & $2.3 \pm 0.1$ & 'no effect \\
\hline $\begin{array}{l}\text { Klebsiella } \\
\text { aerogenes }\end{array}$ & $2.0 \pm 0.2$ & $2.1 \pm 0.2$ & $2.3 \pm 0.2$ & $2.5 \pm(0.1$ & no effect \\
\hline E.coli & bno effect & no effect & $1.9 \pm 0.1$ & $2.0 \pm 0.2$ & no effect \\
\hline
\end{tabular}

a.1 mean of 45 replicates \pm standard deviation; ' mean of 15 replicates of control 
Crude extracts of 7 . harzianum showed a considerable inbibitory effect on Streptococcus viridans, Staphylococcus aureus and $K$ aerogenes at high and low concentrations (Table 2). At low levels, a gradual increase in the amount of the crude extract $(10-40 \mu \mathrm{g})$ demonstrated a slight increase in inhibitory action against the above 3 test bacteria. E.coli indicated sensitivity to crude extracts at 30-40 $\mu \mathrm{g}$ levels and no sensitivity to lower concentrations of the same extracts. Clear inhibition zones of antibacterial activity against Streptococcus and Staphylococcus could not be detected in TLC plates spotted with crude extracts of A. fumigatus and T. harzianum. However, a reduction of the growth of both types of bacteria was seen near the base line in all TLC plates.

Table 2: Mean diameter of the inhibition zones $(\mathrm{cm})$ of test bacterial colonies exposed to aqueous crude extracts of $T$. harzianum compared to sterile water (control).

\begin{tabular}{|c|c|c|c|c|c|}
\hline \multirow[b]{2}{*}{ Test bacteria } & \multicolumn{3}{|c|}{ Level of extract $(\mu \mathrm{g})$} & \multirow[b]{2}{*}{40} & \multirow[t]{2}{*}{ Control } \\
\hline & 10 & 20 & 30 & & \\
\hline $\begin{array}{l}\text { Staphylococcus } \\
\text { aureus }\end{array}$ & $2.0 \pm 0.2$ & $2.3 \pm 0.1$ & $2.5 \pm 0.1$ & $2.8 \pm 0.4$ & no effect \\
\hline $\begin{array}{l}\text { Streptococcus } \\
\text { viridans }\end{array}$ & $" 1.8 \pm 0.3$ & $2.1 \pm 0.2$ & $2.3 \pm 0.2$ & $2.5 \pm 0.2$ & "no elfect \\
\hline $\begin{array}{l}\text { Klebsiella } \\
\text { aerogenes }\end{array}$ & $2.5 \pm 0.2$ & $2.6 \pm 0.2$ & $2.8 \pm 0.2$ & $3.0 \pm 0.2$ & no effect \\
\hline E.coli & "no effect & no effect & $1.8 \pm 0.2$ & $1.8 \pm 0.2$ & no effect \\
\hline
\end{tabular}

a.b mean of 45 replicates \pm standard deviation; ${ }^{\mathrm{c}}$ mean of 15 replicates of control

When antibacterial activity of $A$. fumigatus was tested on 4 test bacteria after solvent extraction and separation into fractions, aqueous extracts from the methanol fraction showed activity against 4 test bacteria. Aqueous extracts from hexane, ethyl acetate, methylene chloride and ether fiactions clid not show any inhibitory effect on the test bacteria. Similarly, aqueous extracts prepared from ethyl acetate and methanol fractions of $T$. harzianum demonstrated antibacterial activity against all 4 test organisms. Aqueous extracts from hexane, methyl chloride and ether fractions did not show any effect on test organisms.

Purification and separation of active fractions of $A$. fumigatus using column and thin layer chromatography resulted in identifying 3 active fractions namely, AM-1, AM-2 and AM-3 in methanol which were later dissolved in water and tested for antibacterial activity. When the above fractions were subjected to disc diffusion bioassay, all three aqueous fractions showed activity against Staphylococcus aureus and Streptococcus viridans. Fraction AM-1 showed the highest activity against Streptococicus and Staphylococcus, whereas AM-2 and AM-3 demonstrated 
similar inhibitory action against the same bacteria compared to the control. (Table 3). When Hamburger \& Cordell TLC bioassay was carried out, only one fraction (AM-1) showed antibacterial activity against Streptococcus viridans and Staphylococcus aureus whereas AM-2 and AM-3 were not active against the same bacteria. The active spot $(\mathrm{Rf}=0.91)$ appeared as a yellow circle of $1 \mathrm{~cm}$ diameter on a pink background on TLC plates.; this antibacterial fraction was labelled as AM1-H.

Table 3: Mean diameter of the inhibitory zones $(\mathrm{cm})$ of test bacterial colonies exposed to 3 aqueous fractions of $A$. fumigatus compared to sterile water (control).

\begin{tabular}{ccc}
\hline & \multicolumn{2}{c}{ Test organism } \\
\hline Fraction & $\begin{array}{c}\text { Streptococcus } \\
\text { viridans }\end{array}$ & $\begin{array}{c}\text { Staphylococcus } \\
\text { aureus }\end{array}$ \\
\hline AM-1 & $2.3 \pm 0.1$ & $2.1 \pm 0.3$ \\
AM-2 & $2.0 \pm 0.2$ & $1.8 \pm 0.1$ \\
AM-3 & $1.9 \pm 0.2$ & $1.8 \pm 0.2$ \\
Control & "no effect & no effect \\
\hline
\end{tabular}

"mean of 45 replicates \pm standard deviation; "mean of 15 replicates of control.

Aqueous fiactions, TE-1, TE-2 and TE-3, which were prepared from T. harzianum ethyl acetate fraction when tested using the Hamburger \& Cordell assay, did not display any antibacterial activity. Four aqueous fractions of T. harzianum - TM-1, TM-2 TM-3 and TM-4 (which were initially extracted to methanol), when tested exhibited considerable antibacterial activity against both Streptococcus viridans and Staphylococcus aureus (Table 4).

Table 4: Mean diameter of the inhibitory zones $(\mathrm{cm})$ of test bacterial colonies exposed to 3 aqueous fractions of $T$. harzianum compared to sterile water (control).

Test organism

\begin{tabular}{ccc}
\hline Fraction & $\begin{array}{c}\text { Streptococcus } \\
\text { viridans }\end{array}$ & $\begin{array}{c}\text { Staphylococcus } \\
\text { aureus }\end{array}$ \\
\hline TM-1 & "3.4 0.2 & $2.9 \pm 0.1$ \\
TM-2 & $3.5 \pm 0.2$ & $3.0 \pm 0.2$ \\
TM-3 & $3.8 \pm 0.1$ & $2.3 \pm 0.2$ \\
TM-4 & $2.0 \pm 0.2$ & $2.0 \pm 0.3$ \\
Control & bno effect & no effect \\
\hline
\end{tabular}

"mean of 45 replicates \pm standard deviation; "mean of 15 replicates of control. 


\section{DISCUSSION}

The present survey indicates the occurrence of thermophilic fungi such as Aspergillus fumigatus, Chaetomium thermophile and Mucor pusillus in straw and oyster compost substrates at different levels of processing. Trichoderma harzianum was also present in all the compost samples tested. Since most of the isolated fungi could theoretically grow at a wide temperature range of $20-58^{\circ} \mathrm{C}$; and Trichoderma around $10-40^{\circ} \mathrm{C}$, compost samples were incubated in an incubator under humid conditions at $30-50^{\circ} \mathrm{C}$ to isolate fungi. Eventhough two separate composting procedures are adapted at EDB, Ratmalana for straw and oyster compost substrates, types of fungi present on both substrates were the same and their frequencies of occurrence were also relatively similar. $M$. pusillus, C. thermophile, A. fumigatus have been reported as thermophilous fungi living in various mushroom composts. ${ }^{1,2}$

A. fumigatus which is considered as a human and animal pathogen, has been recovered previously from soil, compost and plant substrates. ${ }^{5.10} \mathrm{~A}$. fumigatus which is the causal agent of aspergillosis, farmer's lung disease and other related disorders, has also been isolated from body fluids of acquired immunodeficiency syndrome (AIDS) patients. ${ }^{10}$ The above fungus produces many secondary toxic metabolites such as fumitremorgin, gliotoxin, fumitoxin which attack the central nervous system leading to tremorgenic effects in affected individuals. ${ }^{10}$. A. fumigatus which can survive at a range of water activities $\left(\mathrm{a}_{\mathrm{w}}\right)$ from $0.82-0.97$ at $40^{\circ} \mathrm{C}$ has been found to grow on composts at high temperature upto $55^{\circ} \mathrm{C}$ and low oxygen tensions. ${ }^{10}$ Since the above fungus could cause deleterious effects in man, necessary steps should be taken to decontaminate compost before introducing mushroom spawn.

Many different weed moulds have been recognized in compost, competing with mycelia of mushrooms for nutrients, water and space. Weed moulds such as Chaetomium globosum can cause severe reductions in yield if the composting procedure is inefficient or if substrates infested with spores of molds are used in the preparation of compost. "However, Chaetomium thermophile has been identified as a useful fungus which helps to increase temperature in compost piles along with actinomycetes and bacteria, during composting. ${ }^{11}$

Species of Trichoderma namely T. viridae, T. harzianum, T. hamatum and T. koningii which are considered as weed moulds appear as dense green mats on mushroom composts. Results of previous surveys indicate that $10-80 \%$ of bags in mushroom houses in the United Kingdom, being infected with Trichoderma resulting in considerable loss of income for the grower." T. hamatum and T. harzianum can also affect the growth of oyster mushroom (Pleurotus spp.) through the production of a diffusible, non-volatile toxin which has been shown to kill mycelia of the above mushroom. ${ }^{11}$ Wet and improperly pasteurized soil or compost 
components could assist the development of Trichoderma on composts. ${ }^{11}$ Mushroom cultivated on heat treated straw have previously been colonized by the cellulose competing antagonist - T. hamatum. ${ }^{11}$

Relatively high levels (5000-10,000 $\mu \mathrm{g})$ of crude aqueous extract of A.fumigatus when subjected to disc diffusion assay, demonstrated antifungal activity against the three test fungi. The inability to identify inhibition zones during the Cladosporium TLC bioassay could be due to the low polarity of active compounds in crude extracts of $A$. fumigatus. Since lower levels of crude extracts $(<1000 \mu \mathrm{g})$ were not active against test fungi during disc diffusion assay, further studies on antifungal properties were not conducted. Few strains of thermotolerant. A. fumigatus from soil have been shown to produce several antifungal compounds when optimum conditions are provided. A family of antifungal compounds named as "sphingofungins" identified by growing A. fumigatus on solid millet-based medium, has been characterized as potent inhibitors of first enzyme (serine palmitoyl transferase) in the sphingolipid metabolic pathway in mammals. ${ }^{5}$ One of the aims of the present survey was to isolate new antifungal/antibacterial compounds from A. fumigatus grown on yeast extract starch liquid medium.

During our survey we were successful in demonstrating the ability of A. fumigatus in producing antibacterial compound(s) on yeast extract starch medium. Since AM-1 to AM-3 fractions of A. fumigatus were equally sensitive to Streptococcus viridans and Staphylococcus aureus, we believe that our future research in identifying and characterizing purified fractions could make a valuable contribution towards developing new therapeutic agents for the treatment of plant and / or human bacterial diseases.

Present.survey demonstrated the antifungal nature of crude extracts of T. harzianum at fairly high levels $(5000-10,000 \mu \mathrm{g})$ against three phytopathogenic fungi. Since the lower levels $(100-1000 \mu \mathrm{g})$ when tested using disc diffusion bioassays. were not active against all 3 fungi we focussed our research only on antibacterial assays. However, in a recent study of chitinolytic enzymes extracted from $T$. harzianum has demonstrated antifungal activity against Fusarium spp., Pythium and Botrytis, specially in combination with enzymes from Enterobacter cloacae. ${ }^{2}$ Another survey indicated the ability of $T$. harzianum in producing "trichorzins" and "harzianins" (linear peptides belonging to the peptaibol class) on a liquid medium containing glucose and seven mineral salts; trichorzins and harzianins have exhibited antifungal activity against phytopathogenic Sclerotium cepivorum ${ }^{13}$ Another biologically active compound known as "trichodermin". has been isolated from Trichoderma species such as $T$. harzianum, $T$. viridae, $T$. koningii, and $T$. lignorum grown on barley seeds (solid-phase fermentation). ${ }^{14.15}$ Commercial preparations of trichodermin are being used in Russia to manage a wide range of phytopathogenic fungi causing diseases on many economical crops such as tomato, capsi- 
cum, cucumber and cereals. ${ }^{14,15}$ Ability of the Trichoderma in producing antifungal compounds could vary depending on many conditions such as Trichoderma species selected, solid/liquid medium used for fermentation and incubation conditions.

During the present survey, only aqueous TM fractions of T. harzianum exhibited antibacterial activity against Streptococcus viridans and Staphylococcus aureus. This proves that the active compound is fairly nonpolar, hence in future a differtent solvent system will be used as the mobile phase during Hamburger and Cordell bioautographic TLC assay for better separation of active components. Large scale fermentation of $T$. harzianum and $A$. fumigatus on the 2 selected media to obtain fairly high levels of crude extracts has already been initiated. We propose to identify TM and AM fractions from T.harzianum and $A$. fumigatus and purify both fractions using chromatography techniques before elucidating the structures with the aid of NMR and GC-Mass spectroscopy.

\section{Acknowledgement}

We thank NARESA for the research grant - (RG/94/C/003). We gratefully acknowledge the assistance of staff members at EDB research station. We wish to thank Prof. R .L.C. Wijesundera, Department of Botany, University of Colombo for providing pure cultures of plant pathogenic fungi and for his assistance in identifying Trichoderma harzianum. Appreciation is also extended to Dr. W. Herath at Medical Research Institute (MRI) for providing human bacterial pathogenic species. The assistance of the staff of Departments of Botany and Chemistry, at the University of Colombo is deeply appreciated.

\section{References}

1. Hudson H.J. (1980). Thermophilous (thermophilic) fungi. In: Fungal Saprophytism. Second edition. pp. 62-69. Edward Arnold publishers, UKK.

2. Deacon J.W. (1980). Environmental conditions for growth: tolerance of extremes. In: Introduction to modern mycology. Volume 7. pp. 120-130. Blackwell Scientific publications.

3. Coomaraswamy U. \& de Fonseka R.N. (1981). A handbook to the soil fungi of Sri Lanka. Department of Botany, University of Colombo, Sri Lanka.

4. Chakrabarty M., Batabyal A. \& Barua A.K. (1994). New ceramides from the hypotensive extract of a sea anemone, Paracondylactis indicus. Journal of Natural Products 57(3): 393-395. 
5. Van Middlesworth F., et.al. (1992): Sphingofungins A, B, C and D; a new family of antifungal agents: fermentation, isolation and biological activity. Journal of Antibiotics 45(6): 861-867.

6. Hewage C.M. (1989). Biological activity of some Sri Lankan medicinal plants. M.Phil thesis. University of Peradeniya, Sri Lanka.

7. Weerasena J.A., Amarasekera A.S. \& Wijesundara R.L.C. (1990). Antifungal activity of oxidized cashew nut shell liquid. Proc. Sri Lanka Ass. Adumt. Sci. 46:114 (Abstract)

8. Hamburger M.O. \& Cordell G.A. (1987). A direct bioautographic TLC assay for compounds possessing antibacterial activity. Journal of Natural Products 50(1): 19-22.

9. Schwartz R.E., Giacobbe R.A., Bland J.A. \& Monaghan R.L. (1989). L-671,329, A new antifungal agent : fermentation and isolation. Journal of Antibiotics 42(2): 163-167.

10. IMI Descriptions of fungi and bacteria. (1995). Aspergillus fumigatus Description No. 1252. Mycopathologia 132: 45-46.

11. Jeffries P. \& Young I.W.K. (1994). Interfungal parasitic relationships. International Mycological Institute. Egham, Surrey, UK. pp. 170-215.

12. Lorito M., Di Pietro A., Hayes C.K., Woo S.L. \& Harman G.E. (1993). Antifungal synergistic interaction between chitinolytic enzymes from Trichoderma harzianum and Enterobacter cloacae. Molecular Plant Pathology 83(7): 721-728.

13. Goulard C., Hilmi S., Rebuffat S. \& Bodo B. (1995). Trichorzins HA and MA, antibiotic peptides from Trichoderma harzianum : fermentation, isolation and biological properties. Journal of Antibiotics 48(11): 1249-1253.

14. Fatueva G.G. (1993). Industrial production of trichodermin. ZashchitaRastenii-Moskva 4: 48

15. Krivoshchekova T.G. \& Mishchenko V.S. (1990). The effectiveness of Trichodermin. Zaschita-Rastenii-Moskva 11: 22 